\title{
Characterization of Implantation's Biomaterials Based on the Patient and Doctor Expectations
}

\author{
Alijani $\mathbf{S}^{1}$ and Anvari $\mathrm{A}^{2 *}$ \\ ${ }^{1}$ Department of Art and Architecture, Iran \\ ${ }^{2}$ Department of Mechanical and Aerospace Engineering, USA \\ *Corresponding author: Anvari A, Department of Mechanical and Aerospace Engineering, Columbia, Missouri, USA

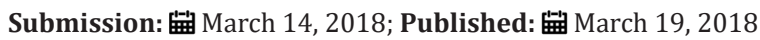

\begin{abstract}
The aim of this research is to characterize the biomaterials for different implant applications in human body. Biomaterials have been used in different parts of human body such as hips, bones, joints, stents, etc. As these materials are using in different parts of human body, they need to represent properties compatible to the required part which is called biocompatibility. Even the expectations of the patient and doctor from the biomaterials implantation surgery can seriously affect the selection of biomaterials. For an instance, if the patient is too old, they may need to use a biomaterial that may dissolve in human body thus the second surgery for implant removal can be eliminated for the patient convenience. The selection of biomaterials that can offer suitable properties is of high significance. In some cases, they need to be tough like bones and joints with enough stiffness. In some implantations, they need to be flexible like stents for heart valves. In some of the cases, they need to be anti-corrosion due to the hostile environment in human body fluid. On the other hand, in some cases they need to dissolve in human body to eliminate the implantation removal surgery. Furthermore, it seems necessary to evaluate the biomaterials based on their fatigue life because they are subjected to cyclic loads in human body. The objective of this study is to characterize the properties of different biomaterials that can help the doctor and the patient to select the best biomaterials based on their expectations from the implantation surgery.
\end{abstract}

Keywords: Titanium; Magnesium; Alloys; Human body fluid

\section{Introduction}

It has been years that scientists and doctors are looking for biomaterials with adequate mechanical properties and biocompatibility to use in human body as a replacement for bones, joints, hips, etc. [1].

In order to investigate the environmental effect of human body on biomaterials, many experimental procedures are performed [2]. In 2017, the role of metallic materials as biomaterials in human body is introduced by Santos [3]. Metallic materials can be used in artificial valves in the heart, stents in blood vessels, replacement implants in shoulder, knees, hips, elbows, ears and ortho dental structures [3]. Recently, Titanium alloys have attracted many researchers due to their excellence biocompatibility [4,5].

Furthermore, numbers of investigations are performed to characterize the corrosion and fatigue resistance of titanium and magnesium alloys. The reason behind is that corrosion of metallic materials in human body is one of the important issues that needs to be studied. This is due to the corrosive environment of human body fluid. In addition, fatigue is due to the cyclic loads in human body as a result of dynamic loads such as walking, running, etc. Among the investigations in this area, "comparative corrosion behavior of titanium alloys for dental implants" is provided by Lopes et al. [6]. "Resistance of Magnesium alloys to corrosion fatigue for biodegradable implant applications" is submitted by Raman \& Harandi [7]. In addition, "fatigue and corrosion fatigue of Ti-6Al$4 \mathrm{~V}$ implant grade Titanium alloy in ringer solution" is presented by Yazdani et al. [8]. Furthermore, recently, numbers of studies to predict the fatigue life and failure of materials are provided by Anvari [9-13].

\section{Magnesium against natural bone}

Table 1: Comparison of the mechanical properties of natural bone with magnesium implants [9].

\begin{tabular}{|c|c|c|}
\hline Properties & Natural Bone & Magnesium \\
\hline Density $\left(\mathrm{g} / \mathrm{cm}^{3}\right)$ & $1.7-2.0$ & $1.74-2.0$ \\
\hline Elastic Modulus (MPa) & $3-20$ & $41-45$ \\
\hline $\begin{array}{c}\text { Tensile Strength } \\
(\mathrm{MPa})\end{array}$ & $80-150$ & $170-270$ \\
\hline $\begin{array}{c}\text { Compressive Yield } \\
\text { Strength (MPa) }\end{array}$ & $130-180$ & $65-100$ \\
\hline $\begin{array}{c}\text { Elongation at Failure } \\
(\%)\end{array}$ & $1-7$ & $6-20$ \\
\hline $\begin{array}{c}\text { Fracture Toughness } \\
\left(\mathrm{MPa} \mathrm{m}^{1 / 2}\right)\end{array}$ & $3-6$ & $15-40$ \\
\hline
\end{tabular}

In Table 1 [14], mechanical properties of natural bone and Magnesium are indicated. With a quick review of the mechanical properties of natural bone and Magnesium, it can be concluded 
that the values of the material properties of natural bone and Magnesium are close to each other. With the further assessment of Table 1, it is easy to find out that the value of density in natural bone (1.7 to $2.0 \mathrm{~g} / \mathrm{cm}^{3}$ ) is approximately in the same range as Magnesium density ( 1.74 to $2.0 \mathrm{~g} / \mathrm{cm}^{3}$ ). It is one of the reasons that Magnesium is one of the best biomaterials for the application of implantations in human body as is a perfect match with natural bone based on density.

\section{Conclusion}

In the case of choosing biomaterials as implantations in human body, many options are introduced. Among these options, it seems that Magnesium and its alloys are very suitable to use as biomaterials in human body because of their excellent mechanical properties. In addition, Magnesium and its alloys seem to be biocompatible with human body environment and consequently, it appears they have no harm for human body. Moreover, these biomaterials can dissolve in human body fluid hence they can prevent from second surgery. Avoiding second surgery is very useful because sometimes the patient is too old for the second surgery. Furthermore, generally, doctors and patients are always looking for ways to reduce the numbers of surgery.

\section{Acknowledgement}

All the funding related to this research is provided by the presented authors.

\section{References}

1. Sedmak A, Rakin M (2006) Biomaterials joints and problems of contact interfaces. FME Transactions 34(2): 81-86.

2. Dewidar M (2012) Influence of processing parameters and sintering atmosphere on the mechanical properties and microstructure of porous 316L stainless steel for possible hard-tissue applications. International Journal of Mechanics \& Mechatronics Engineering 12(1):10-24.
3. Santos GAD (2017) The importance of metallic materials as biomaterials. Advances in Tissue Engineering and Regenerative Medicine 3(1): 1-3.

4. Wang SP, Xu J (2017) TiZrNbTaMo high-entropy alloy designed for orthopedic implants: As-cast microstructure and mechanical properties. Materials Science and Engineering: C 73:80-89.

5. Findik F (2017) Titanium Based Biomaterials. Engineering \& Biosciences $7(3): 1-3$.

6. Lopes CSD, Donato MT, Ramgi P (2016) Comparative corrosion behavior of titanium alloys (Ti-15Mo and Ti-6Al-4V) for dental implants applications: A review. Corrosaoe Proteccao De Materials 35(2): 1-30.

7. Raman RKS, Harandi SE (2017) Resistance of magnesium alloys to corrosion fatigue for biodegradable implant applications: current status and challenges. Materials 10(11): 1-11.

8. Yazdani SY, Hajisafari M, Bidaki AZ (2017) Fatigue and corrosion fatigue of Ti-6Al-4V implant grade titanium alloy in ringer solution. Journal of Advanced Materials and Processing 5(3): 12-22.

9. Anvari A (2014) Fatigue life prediction of unidirectional carbon fiber/ epoxy composite in Earth orbit. Int J Appl Math Mech 10(5): 58-85.

10. Anvari A (2017) Crack growth as a function of temperature variation in carbon fiber/epoxy. Journal of Chemical Engineering and Materials Science 8 (3): 17-30.

11. Anvari A (2017) Failure of Nickel-based super alloy (ME3) in aerospace gas turbine engines. Journal of Chemical Engineering and Materials Science 8 (6): 46-65.

12. Anvari A (2017) Thermal fatigue life of carbon nano tube wire and unidirectional carbon fiber/epoxy composite (UCFEC) in earth orbit. Journal of Chemical Engineering and Materials Science 8(8): 101-111.

13. Anvari A (2017) Fatigue life prediction of unidirectional carbon fiber/ epoxy composite on mars. Journal of Chemical Engineering and Materials Science 8(8): 74-100.

14. Peron M, Torgersen J, Berto F (2017) Mg and its alloys for biomedical applications: exploring corrosion and its interplay with mechanical failure. Metals 7: 1-41.
Creative Commons Attribution 4.0 International License

For possible submissions Click Here

\section{Submit Article}

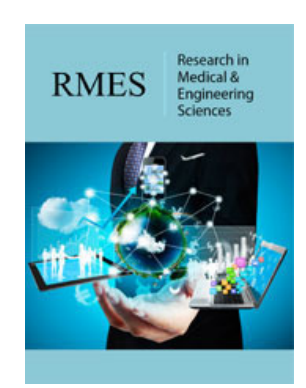

\section{Research in Medical \& Engineering Sciences}

\section{Benefits of Publishing with us}

- High-level peer review and editorial services

- Freely accessible online immediately upon publication

- Authors retain the copyright to their work

- Licensing it under a Creative Commons license

- Visibility through different online platforms 